\title{
Gas Transport Properties of Various Imidized Polyamic Acid Films
}

\author{
Hisao Hachisuka, Yoshiharu.Tsujita, * Akira Takizawa, \\ and Takatoshi KINOSHITA \\ Department of Materials Science and Engineering, \\ Polymeric Materials Course, Nagoya Institute of Technology, \\ Gokiso-cho, Showa-ku, Nagoya 466, Japan
}

(Received December 22, 1988)

\begin{abstract}
The sorption and permeation of $\mathrm{CO}_{2}$ in and through various imidized polyamic acid [PAA] films were investigated. Dual-mode sorption and partial immobilization models were applied to their phenomena and their behavior and structure are discussed. The amount of $\mathrm{CO}_{2}$ sorption increased with imidization in PAA film up to the imide content of $c a .40 \%$, and then decreased. This behavior can be attributed mainly to the variation of the Langmuir sorption capacity term $\left(C_{\mathbf{H}}{ }^{\prime}\right)$. In other words, it can be regarded that an unrelaxed volume and/or a microvoid fraction $\left[\left(V_{\mathrm{g}}-V_{1}\right) / V_{\mathrm{g}}\right]$ vary with imidization, which are functions of $T_{\mathrm{g}}$ and difference in the expansion coefficient between liquid and glassy states. $C_{\mathrm{H}}$ ' was described by the product $\left(T_{\mathrm{g}}-25\right)$ and $\Delta C_{\mathrm{p}}$, difference of heat capacity between liquid and glassy states used instead of the expansion coefficient. On the other hand, the diffusion coefficient of Henry's law mode $\left(D_{\mathrm{D}}\right)$ is enhanced by the decrease of carboxyl group in PAA reducing the diffusion of penetrant with imidization up to $c a$. $40 \%$, and then is depressed by restricted thermal mobility caused by considerably increased rigidity in the polymer chain with imidization. Variation in the diffusion coefficient of Langmuir mode behaved parallelly to $D_{\mathrm{D}}$.
\end{abstract}

KEY WORDS Polyamic Acid / Imidization / Dual-Mode Sorption Model /

Partial Immobilization Model / $\mathrm{CO}_{2}$ Gas Transport / Microvoid /

Glassy polymer films are effective as permselective films since their permeability is relatively high owing to the presence of an unrelaxed volume and/or a microvoid in spite of poor segmental mobility, and mechanical properties of glassy polymer are superior to those of rubbery polymer in mechanical strength and heat-stability, etc. It is important to clarify the transport mechanism of glassy polymer film in order to develop glassy permselective membranes. In particular, it is noteworthy that polyimide [PI] film, which has a higher $T_{\mathrm{g}}$ and more heat-stability, can be used in a gas separation system operated at high temperature. $^{1-5}$

* To whom correspondence should be addressed
It is known that the PI [poly $\left(4,4^{\prime}\right.$-oxydiphenyl pyromellitimide)] used in this study is synthesized through the condensation of pyromellitic acid dianhydride and 4,4'-diaminodiphenyl ether. The initial condensation product, a polyamic acid (polypyromellic acid) [PAA] precursor is usually heated to complete the imidization reaction. Earlier studies have been reported on the properties and structure of PI. ${ }^{6}$ It has been also found that the physical properties, $T_{\mathrm{g}}$, density, etc., of PAA vary by imidization. Various imidized PAA films are interesting and useful to elucidate their sorption and permeation mechanisms because their films have various structures with differ- 
ing $T_{\mathrm{g}}$. It is expected that the effect of partial imidization might provide favorable transport properties.

In previous studies ${ }^{7-9}$ we reported the gas sorption and permeation in and through the glassy polymer films which have various thermal histories. The changes in the transport properties of these films can be attributed to the fact that the Langmuir sorption capacity term $\left(C_{\mathbf{H}}\right.$ ') and two diffusion coefficients according to both Henry's law and Langmuir modes depend on the thermal history.

In this study sorption and permeation measurements were performed at $25^{\circ} \mathrm{C}$ at pressure up to $1000 \mathrm{cmHg}$, and the influence of imidization in PAA films on $\mathrm{CO}_{2}$ transport properties was examined by applying the dualmode sorption ${ }^{10,11}$ and partial immobilization models ${ }^{12-14}$. The relationship between transport properties and imidization is discussed from the viewpoint of the variation of $C_{\mathrm{H}}$ ' and primary structure of PAA.

\section{EXPERIMENTAL}

\section{Materials}

PAA film was supplied kindly by the Nissan Chemical Industries, Ltd. PAA film was cast from the $N$-methylpyrrolidone solution in which pyromellitic acid dianhydride and $4,4^{\prime}$ diaminodiphenyl ether were condensed, and was dried at $100^{\circ} \mathrm{C}$ for $1 \mathrm{~h}$. It is known that PAA can be intramolecularly cyclized to PI by heating as follows:

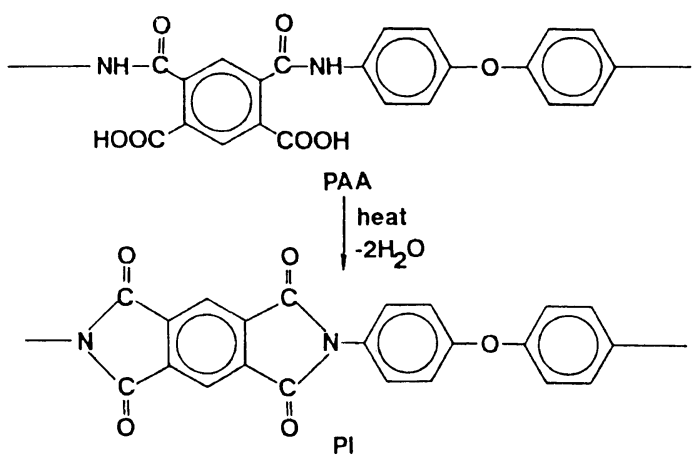

PAA films were imidized at vacuum $\left(<10^{-3} \mathrm{mmHg}\right.$ ) for various periods, 50, 100, 200 , and $400 \mathrm{~h}$, at $150^{\circ} \mathrm{C}$ after complete drying at vaccum $\left(<10^{-3} \mathrm{mmHg}\right)$ at room temperature. The thickness of the obtained films ranged from 50 to $70 \mu \mathrm{m}$. PI film (the thickness is $c a .12 .5 \mu \mathrm{m}$ ), which has an imide content of $100 \%$, was supplied kindly by the Kanegafuchi Chemical Industry Co., Ltd. Imide content of various imidized PAA films was characterized by using an infrared spectroscopy (IR) [IR-700, Japan Spectroscopic Co., Ltd.] on the basis of ATR method [ATR-61].

Densities of various imidized PAA films were determined at $25^{\circ} \mathrm{C}$ by the floating method using a mixed solvent of $n$-hexane and carbon tetrachloride.

Heat capacity and $T_{\mathrm{g}}$ of various imidized PAA films were obtained by using a differential scanning calorimetry (DSC) [SSC 560, Seiko Electronics Co., Ltd.]. Glass transition temperature $\left(T_{\mathrm{g}}\right)$ of unimidized PAA and PI films were $c a .155^{\circ} \mathrm{C}$ and $410^{\circ} \mathrm{C}$, respectively.

\section{Method}

The films sealed with a teflon ring was degassed for $24 \mathrm{~h}$ at $10^{-4} \mathrm{mmHg}$ in a permeation apparatus. The permeation measurement is as follows: evacuation of a downstream side of the film up to about $10^{-4}$ $\mathrm{mmHg}$, introduction of permeant gas to an up-stream side and the monitoring permeated gas pressure in the down-stream side using a MKS-Baratron pressure transducer (227AA). The permeability coefficient was evaluated by a steady gas parmeation rate.

Sorption measurement was carried out by using a gravimetric sorption apparatus with electromicrobalance the Cahn-2000 (Cahn Instruments, Inc.). After sufficiently drying the films at about $10^{-4} \mathrm{mmHg}$, the amount of $\mathrm{CO}_{2}$ gas sorbed in a film under a certain fixed pressure was corrected by subtracting a buoyancy contribution.

The magnitude of purity of $\mathrm{CO}_{2}$ used in the 
sorption and permeation measurements was of a greater purity than $99.9 \%$ and was used without further purification.

\section{RESULTS AND DISCUSSION}

\section{Imidization}

PAA films were imidized under vacuum for various periods at $150^{\circ} \mathrm{C}$. The IR spectrum of PAA film imidized for $200 \mathrm{~h}$ at $150^{\circ} \mathrm{C}$ is illustrated in Figure 1 in contrast to those of unimidized PAA and PI films. The absorbance in the vicinity of $880 \mathrm{~cm}^{-1}$ is assigned to the deformation vibration of isolated $\mathrm{C}-\mathrm{H}$ attached to a phenyl ring, which is independent of imide content and is regarded as an internal

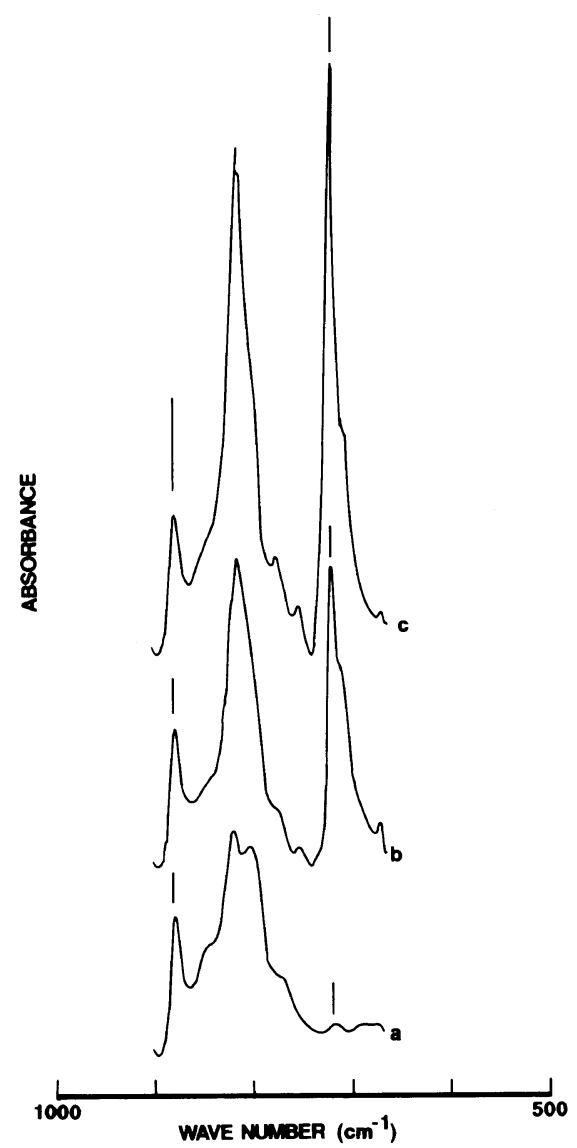

Figure 1. Infrared absorption spectra of unimidized PAA film (a), PAA film imidized for $200 \mathrm{~h}$ at $150^{\circ} \mathrm{C}$ (b), and PI film (c). standard to determine imide content. The absorbance in the vicinity of $725 \mathrm{~cm}^{-1}$ was assigned to an out-of-plane carbonyl bending vibration $^{15}$ and its intensity increased with imidization of PAA film. A similar spectrum variation was observed for another PAA film. The change in intensity at $725 \mathrm{~cm}^{-1}$ can be used to determine imide content using an internal standard at $880 \mathrm{~cm}^{-1}$. The imide content obtained is shown in Figure 2 as a function of imidization periods at $150^{\circ} \mathrm{C}$. The density of various imidized PAA films is also shown in Figure 2.

\section{Sorption Properties}

Figure 3 shows the $\mathrm{CO}_{2}$ sorption isotherms at $25^{\circ} \mathrm{C}$ of various imidized PAA films. The dashed line in Figure 3 shows the data of as received PI reported previously by us. ${ }^{9}$ The amount of $\mathrm{CO}_{2}$, sorption increased with imidization up to $\mathrm{ca}$. $40 \%$ over the entire pressure range. However, the decrease in $\mathrm{CO}_{2}$ sorption amount was observed when imide content exceeded $c a$. $40 \%$ This sorption behavior can be explained by applying the dualmode sorption model represented by the following equation, ${ }^{10,11}$

$$
C=C_{\mathrm{D}}+C_{\mathrm{H}}=k_{\mathrm{D}} p+\frac{C_{\mathrm{H}}{ }^{\prime} b p}{1+b p}
$$

where $C$ is the total penetrant concentration, $C_{\mathrm{D}}$ is the penetrant concentration due to

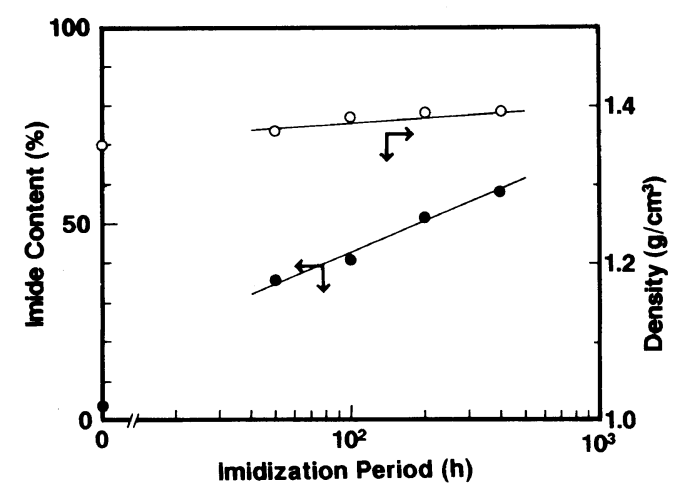

Figure 2. Imide content and density of various imidized PAA films against imidization period at $150^{\circ} \mathrm{C}$. 


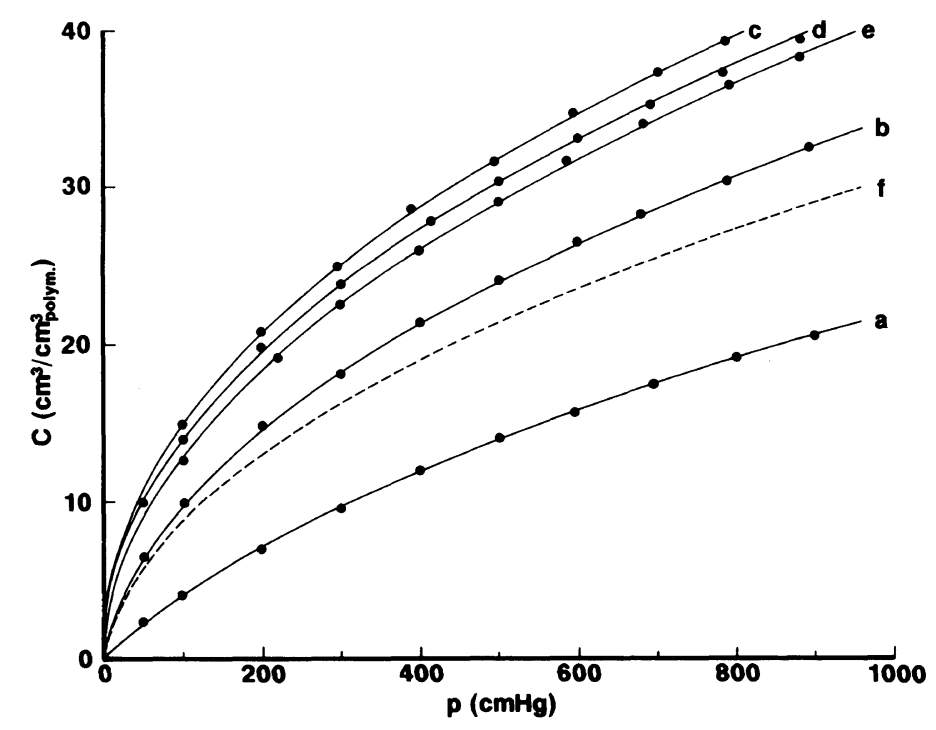

Figure 3. $\mathrm{CO}_{2}$ sorption isotherms at $25^{\circ} \mathrm{C}$ of PAA films imidized for various periods at $150^{\circ} \mathrm{C}: \mathrm{a}, 0 \mathrm{~h} ; \mathrm{b}$, $50 \mathrm{~h} ; \mathrm{c}, 100 \mathrm{~h}$; d, $200 \mathrm{~h}$; e, $400 \mathrm{~h}$; f, PI film. ${ }^{9}$ The closed circles are experimental data and the solid line corresponds to the calculated curve based on the dual-mode sorption model (eq 1).

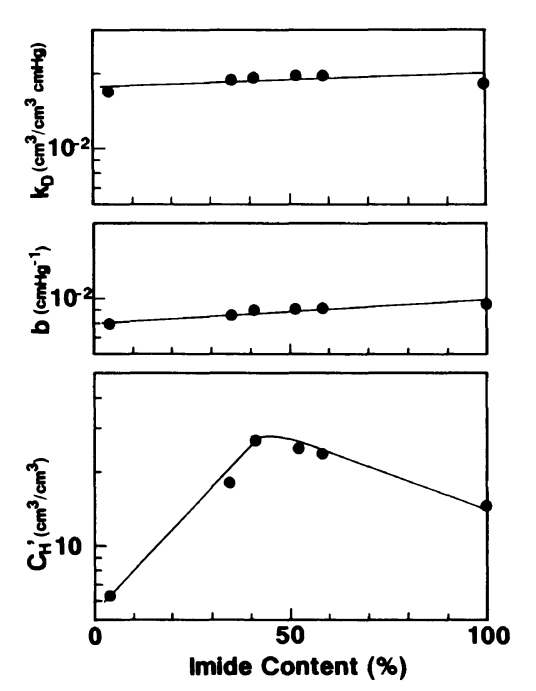

Figure 4. Imide content dependence of dual-mode sorption prameter, $k_{\mathrm{D}}, b$, and $C_{\mathrm{H}}$ ' for $\mathrm{CO}_{2}$ of various imidized PAA and $\mathrm{PI}^{9}$ films.

Henry's law contribution, $C_{\mathrm{H}}$ is the concentration of penetrant held in "microvoid" or Langmuir sorption site, $k_{\mathrm{D}}$ is the Henry's law constant, $p$ is the pressure of penetrant at equilibrium, $b$ is the affinity constant of pene- trant to the Langmuir site, and $C_{\mathrm{H}}$ ' is the hole saturation constant in the Langmuir sorption mode. It might be assumed that this sorption behavior is attributed mainly to the variation of Langmuir-mode sorption process. One can evaluate dual-mode sorption parameters in eq 1 by the non-linear least square method using isotherm data. The parameters obtained are shown in Figure 4 as a function of imide content. $k_{\mathrm{D}}$ and $b$ increased slightly with imidization, indicating a slight change in primary structure and affinity to the microvoid of various imidized PAA films. The $C_{\mathbf{H}}$ ' increased with imidization up to $c a .40 \%$, and then decreased obviously.

In general, Langmuir-mode sorption is interpreted by the sorption of $\mathrm{CO}_{2}$ gas with a liquid-like volume into an unrelaxed volume and/or a microvoid of glassy polymers. Namely, $C_{\mathrm{H}}$ ' is represented by the following equation, ${ }^{16-18}$

$$
C_{\mathrm{H}}{ }^{\prime}=22400\left(\frac{V_{\mathrm{g}}-V_{1}}{V_{\mathrm{g}}}\right) \frac{1}{V_{\mathrm{CO}_{2}}}
$$

where $\left(V_{\mathrm{g}}-V_{1}\right) / V_{\mathrm{g}}$ is the unrelaxed volume 
fraction, the difference between the observed specific volume at the glassy state $\left(V_{\mathrm{g}}\right)$ and the volume at super cooled equilibrium liquid state $\left(V_{1}\right)$ to the $V_{\mathrm{g}}$, and $V_{\mathrm{CO}_{2}}$ is the molar volume of liquid-like $\mathrm{CO}_{2}$ in the Langmuir sorption site. The unrelaxed volume fraction can be also related to $T_{\mathrm{g}}$ by the following expression,

$$
\begin{aligned}
\left(V_{\mathrm{g}}-\right. & \left.V_{1}\right) / V_{\mathrm{g}} \\
& =\left(\alpha_{1}-\alpha_{\mathrm{g}}\right)\left(T_{\mathrm{g}}-T\right) /\left\{1-\alpha_{\mathrm{g}}\left(T_{\mathrm{g}}-T\right)\right\} \\
& \fallingdotseq\left(\alpha_{1}-\alpha_{\mathrm{g}}\right)\left(T_{\mathrm{g}}-T\right)
\end{aligned}
$$

where $\alpha_{1}$ and $\alpha_{\mathrm{g}}$ are the thermal expansion coefficients for liquid and glassy states, respectively.

A specific volume of polymer can be discussed parallelly with enthalpy. A difference between heat capacities at liquid and glassy states at $T_{\mathrm{g}}\left(\Delta C_{\mathrm{p}}=C_{\mathrm{p}_{1}}-C_{\mathrm{p}_{\mathrm{g}}}\right)$ is used instead of $\left(\alpha_{1}-\alpha_{\mathrm{g}}\right)$ as the measure of variation in $C_{\mathrm{H}}$. Therefore, the enthalpy difference between glassy and liquid states at $T_{\mathrm{g}}\left(H_{\mathrm{g}}-H_{1}\right)$ can be expressed by the following equation corresponding to eq 3 ,

$$
H_{\mathrm{g}}-H_{1}=\Delta C_{\mathrm{p}}\left(T_{\mathrm{g}}-T\right)
$$

$C_{\mathrm{H}}$ ' of $\mathrm{CO}_{2}$ gas is related to the $T_{\mathrm{g}}$ of polymer through eq 3 or 4 . When the difference in $\left(\alpha_{1}-\alpha_{\mathrm{g}}\right)$ or $\Delta C_{\mathrm{p}}$ is assumed to be constant, the larger the difference between $T_{\mathrm{g}}$ and observation temperature, the higher is $C_{\mathrm{H}}$ ' according to eq 3 and 4 . It has been reported that $C_{\mathrm{H}}$, of commonly used glassy polymer is approximately proportional to $\left(T_{\mathrm{g}}-T\right) \cdot{ }^{16-19} T_{\mathrm{g}}$ of PAA film studied here increased from $c a$. $155^{\circ} \mathrm{C}$ of unimidized PAA to $c a .410^{\circ} \mathrm{C}$ of PI with imidization. However $C_{\mathbf{H}}$ ' did not increase proportionally, but decrease clearly in spite of the increase of $T_{\mathrm{g}}$ when imide content exceeds $\mathrm{ca} .40 \%$. This behavior suggests that $\left(\alpha_{1}-\alpha_{\mathrm{g}}\right)$ and/or $\Delta C_{\mathrm{p}}$ decrease with imidization, reflecting the rigidity of the polymer chain. It can be considered that the variation in $C_{\mathrm{H}}$, of various imidized PAA films is caused by both raising of $T_{\mathrm{g}}$ and decrease of $\left(\alpha_{1}-\alpha_{\mathrm{g}}\right)$ and/or $\Delta C_{\mathrm{p}}$.
Heat capacities of PAA of various imide content were measured carefully by DSC on the basis of the heat capacity of sapphire as a standard sample, because the $\left(\alpha_{1}-\alpha_{\mathrm{g}}\right)$ cannot be obtained precisely. The temperature dependence of the heat capacities of PAA films is shown in Figure 5. $T_{\mathrm{g}}$ of each PAA film was observed at the bar point in Figure 5 . In the $C_{\mathrm{p}}$ curves of PAA films imidized for 0 and $50 \mathrm{~h}$, an endothermic peak which might be caused by imidization during DSC measurement in the vicinity of $T_{\mathrm{g}}$ was observed. Although $\Delta C_{\mathrm{p}}$ has to be determined as the difference of $C_{\mathrm{p}}$ between liquid and glassy states at $T_{\mathrm{g}}, \Delta C_{\mathrm{p}}$ of PAA films imidized for 0 and $50 \mathrm{~h}$ could not be obtained due to the endothermic peak. $\Delta C_{\mathrm{p}}$ of PAA films imidized at $150^{\circ} \mathrm{C}$ for 100,200 , and $400 \mathrm{~h}$ is listed in Table I with their $T_{\mathrm{g}}$. The

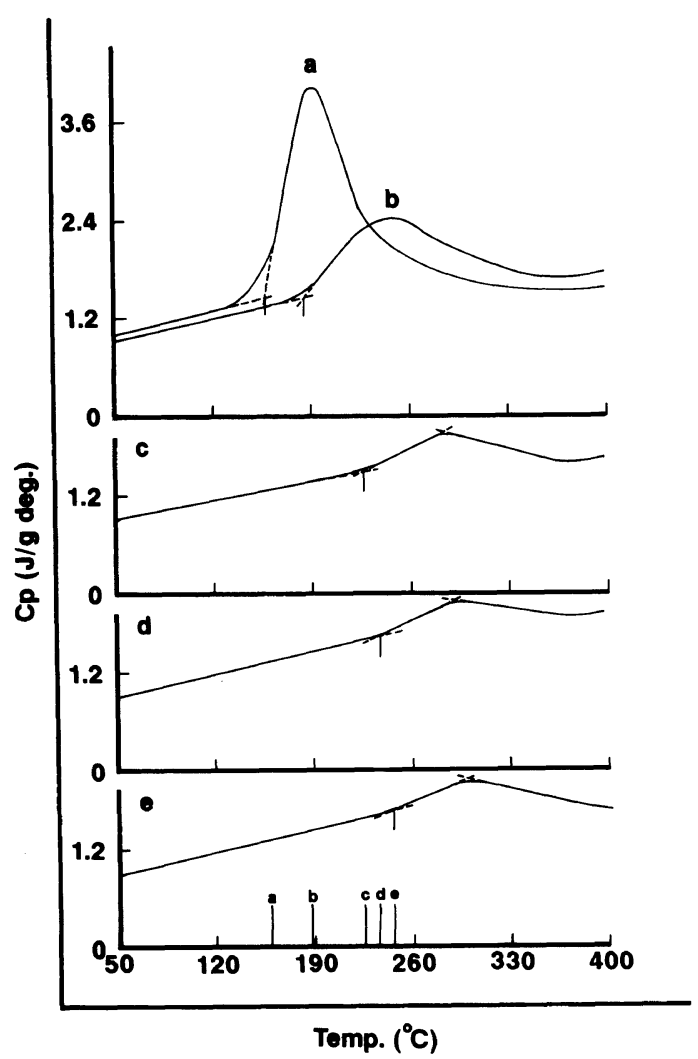

Figure 5. Heat capacity $\left(C_{\mathrm{p}}\right)$ of PAA films imidized for various periods: a, $0 \mathrm{~h}$; b, $50 \mathrm{~h} ; \mathrm{c}, 100 \mathrm{~h} ; \mathrm{d}, 200 \mathrm{~h} ; \mathrm{e}, 400 \mathrm{~h}$ at $150^{\circ} \mathrm{C}$. 
Table I. $T_{\mathrm{g}}, C_{\mathrm{H}}{ }^{\prime}, \Delta C_{\mathrm{p}}$ of various imidized PAA films

\begin{tabular}{|c|c|c|c|c|c|}
\hline \multirow{2}{*}{ Sample } & \multirow{2}{*}{$\begin{array}{l}\text { Imidization period } \\
\text { at } 150^{\circ} \mathrm{C} \\
\mathrm{h}\end{array}$} & \multirow{2}{*}{$\frac{T_{\mathrm{g}}}{{ }^{\circ} \mathrm{C}}$} & \multirow{2}{*}{$\frac{C_{\mathrm{H}}}{\mathrm{cm}^{3} \mathrm{~cm}^{-3}}$} & \multirow{2}{*}{$\frac{\Delta C_{\mathrm{p}}}{\mathrm{Jg}^{-1} \mathrm{deg}^{-1}}$} & \multirow{2}{*}{$\frac{\Delta C_{\mathrm{p}}\left(T_{\mathrm{g}}-25\right)}{\mathrm{Jg}^{-1}}$} \\
\hline & & & & & \\
\hline \multirow[t]{3}{*}{ PAA } & 100 & 227.1 & 26.9 & 0.463 & 93.6 \\
\hline & 200 & 234.1 & 24.5 & 0.408 & 85.3 \\
\hline & 400 & 244.6 & 23.5 & 0.365 & 80.1 \\
\hline
\end{tabular}

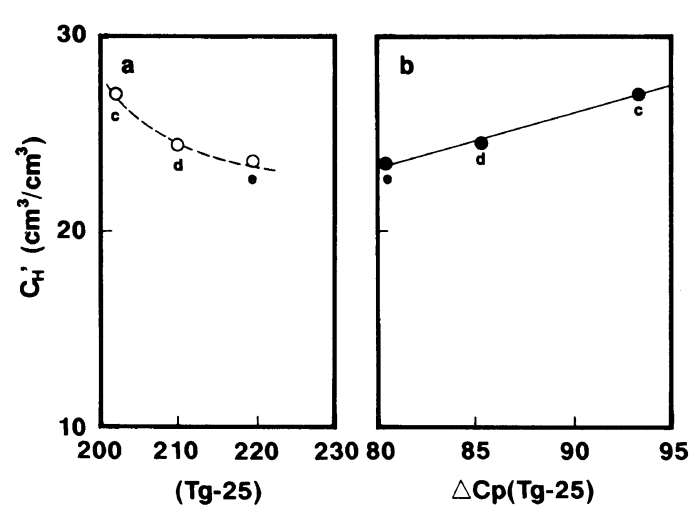

Figure 6. Relationship between $C_{\mathrm{H}}$ ' and $\left(T_{\mathrm{g}}-25\right)$ (a) and $\Delta C_{\mathrm{p}}\left(T_{\mathrm{g}}-25\right)(\mathrm{b})$ of PAA films imidized for various periods: c, $100 \mathrm{~h}$; d, $200 \mathrm{~h}$; e, $400 \mathrm{~h}$.

values decreased with increase of $T_{\mathrm{g}}$. Figures 6(a) and (b) show the variation in $C_{\mathrm{H}}$, of three PAA films listed in Table $I$ as a function of $\left(T_{\mathrm{g}}-25\right)$ and $\Delta C_{\mathrm{p}}\left(T_{\mathrm{g}}-25\right)$, respectively. The linear relationship between $C_{\mathrm{H}}$, and $\left(T_{\mathrm{g}}-25\right)$ which is attained for usual glassy polymers could not be obtained, but $C_{\mathrm{H}}$ ' was proportional to $\Delta C_{\mathrm{p}}\left(T_{\mathrm{g}}-25\right)$. This result supports the prediction mentioned above and suggests that the variation in $C_{\mathrm{H}}$ ' must depend on both $\Delta C_{\mathrm{p}}$ or $\left(\alpha_{1}-\alpha_{\mathrm{g}}\right)$ and $\left(T_{\mathrm{g}}-T\right)$.

\section{Permeation Properties}

Figure 7(a) shows the pressure dependence of the $\mathrm{CO}_{2}$ permeability coefficient at $25^{\circ} \mathrm{C}$ through various imidized PAA films. The dashed line in Figure 7(a) shows the data of as received PI film previously reported by us. ${ }^{9}$ The decreasing trend of permeability coefficient with pressure, which is characteristic of gas permeation through glassy polymers, was observed for each PAA film. The permeability coefficient at a fixed pressure increased with imidization up to $c a .40 \%$, and then decreased. The pressure dependence of permeability coefficient can be analyzed by applying the partial immobilization model represented by the following equation, ${ }^{12-14}$

$$
\bar{P}=k_{\mathrm{D}} D_{\mathrm{D}}+\frac{D_{\mathrm{H}} C_{\mathrm{H}}{ }^{\prime} b}{1+b p}
$$

which was derived by assuming the individual diffusion coefficient for Henry's law mode and Langmuir mode, $D_{\mathrm{D}}$ and $D_{\mathrm{H}}$, respectively. Figure 7 (b) demonstrates the plots of the permeability coefficient of various imidized PAA films as a function of $(1+b p)^{-1}$. The agreement between the calculated line according to eq 5 and experimental data is excellent as seen for other glassy polymers which obey the partial immobilization model. The intercepts of these lines on the high- and lowpressure sides $(p=\infty$ and $p=0)$ correspond to the values of $k_{\mathrm{D}} D_{\mathrm{D}}$ and $k_{\mathrm{D}} D_{\mathrm{D}}+D_{\mathrm{H}} C_{\mathrm{H}}{ }^{\prime} b$ in eq 5 , respectively. Once one knows the dualmode sorption parameters, the two diffusion coefficients, $D_{\mathrm{D}}$ and $D_{\mathrm{H}}$, can be determined from the slope and the intercept in the high pressure range in Figure 7 (b) by the nonlinear least square method.

$D_{\mathrm{D}}$ and $D_{\mathrm{H}}$ are shown in Figure 8 as a function of imide content. $D_{\mathrm{D}}$ increased gradually up to an imide content of $c a .40 \%$, and then decreased. It might be considered that carboxyl groups in PAA may hinder the diffusion of $\mathrm{CO}_{2}$ molecules. ${ }^{20}$ The increase in $D_{\mathrm{D}}$ 

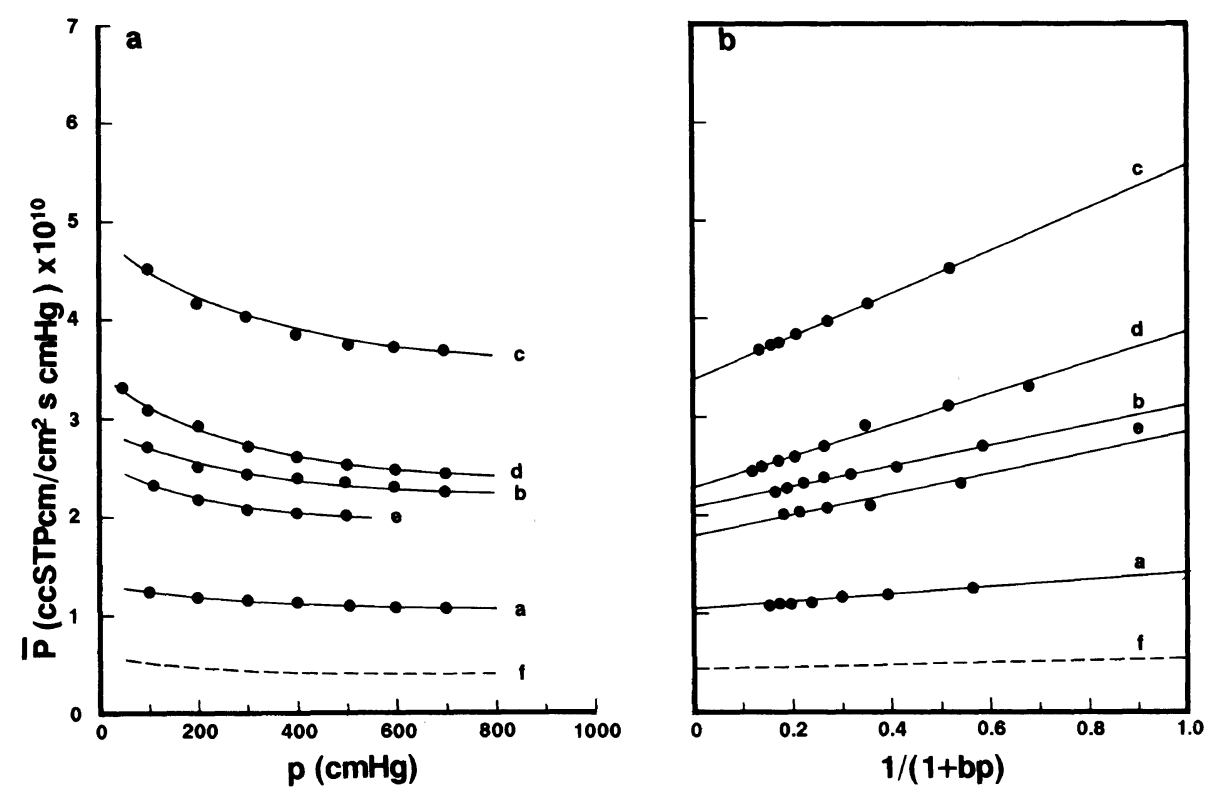

Figure 7. (a) Pressure dependence of permeability coefficients at $25^{\circ} \mathrm{C}$, and (b) permeability coefficients plotted in accordance with the partial immobilization model (eq 5) for $\mathrm{CO}_{2}$ of PAA films imidized for various periods at $150^{\circ} \mathrm{C}$ : a, $0 \mathrm{~h} ; \mathrm{b}, 50 \mathrm{~h} ; \mathrm{c}, 100 \mathrm{~h}$; d, $200 \mathrm{~h}$; e, $400 \mathrm{~h}$; f, PI film. ${ }^{9}$

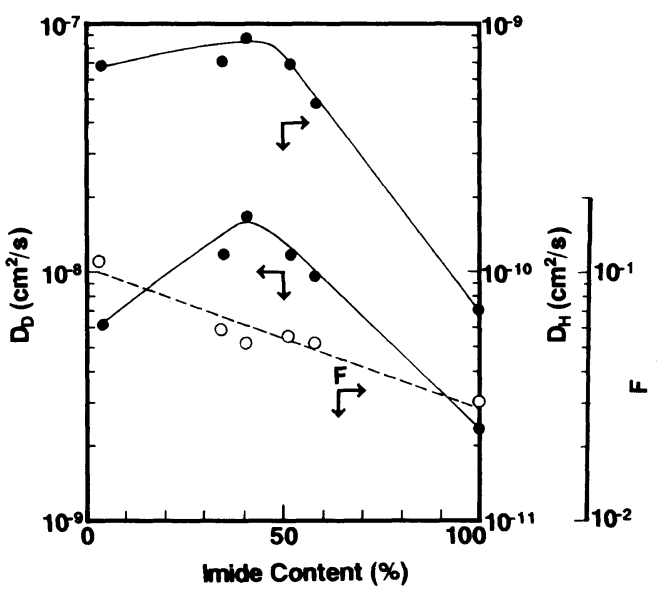

Figure 8. Imide content dependence of diffusion coefficients of Henry- and Langmuir-modes and its ratio $F\left(=D_{\mathrm{H}} / D_{\mathrm{D}}\right)$ for $\mathrm{CO}_{2}$ of various imidized PAA and $\mathrm{PI}^{9}$ films.

can be attributed to the fact that the reduction of the number of carboxyl groups during imidization accelerated the $\mathrm{CO}_{2}$ diffusivity, overcoming the depression of $\mathrm{CO}_{2}$ diffusivity due to enhanced rigidity subject to initial imidization. It is assumed that $D_{\mathrm{D}}$ decreased by an overwhelming depression of $\mathrm{CO}_{2}$ diffusivity in spite of much reduction of carboxyl groups when the imide content exceeded $c a$. $40 \%$. On the other hand, $D_{\mathrm{H}}$ also behaved in a similar manner to $D_{\mathrm{D}}$. It can be assumed that the diffusivity of $\mathrm{CO}_{2}$ molecules sorbed by the Langmuir mode might be accelerated by increase in $C_{\mathrm{H}}$ ' up to an imide content of $c a$. $40 \%$, and then might decrease reflecting reduction of $C_{\mathrm{H}}{ }^{\prime}$. This means that $\mathrm{CO}_{2}$ molecules diffuse more easily with increase in $C_{\mathrm{H}}$, which indicates increase in the size and/or number of microvoids. The decrease in $D_{\mathrm{H}}$ above $c a .40 \%$ was more marked. This might be attributed to the fact the rigidity of the polymer chain caused by imidization also depressed the diffusivity of $\mathrm{CO}_{2}$ molecules sorbed by Langmuir mode. As a result, the two diffusion coefficients of PAA film having imide content of $c a .40 \%$ might be higher.

The ratio between two diffusion coefficients $\left[F=D_{\mathrm{H}} / D_{\mathrm{D}}\right]$ is also shown in Figure 8 . The decrease in $F$ with imidization suggests that the $\mathrm{CO}_{2}$ molecules sorbed by Langmuir mode are 
immobilized considerably by enhancement of the rigidity in the polymer chain.

In conclusion, the amount of $\mathrm{CO}_{2}$ sorption and $\mathrm{CO}_{2}$ permeability coefficient increased with imidization in PAA films up to an imide content of $c a .40 \%$, and then decreased. This behavior can be attributed mainly to variation in $C_{\mathrm{H}}$ '. The variation in $C_{\mathrm{H}}$ ' was represented adequately by a function of $\Delta C_{\mathrm{p}}\left(T_{\mathrm{g}}-25\right)$.

On the other hand, $D_{\mathrm{D}}$ is accelerated by decrease in carboxyl groups in PAA with imidization up to $c a .40 \%$, and then decreases by depressed molecular motion caused by the increase in the rigidity in the main chain with imidization in spite of the decrease in carboxyl groups. The variation in $D_{\mathrm{H}}$ is related to change in $C_{\mathrm{H}}$, and rigidity of the segment. Further studies on the gas separation using various imidized PAA films with different microvoids will be carried out.

Acknowledgements. The authors gratefully acknowledge the partial financial support from the Grant-in-Aid for Scientific Research (No. 63604546) on Priority Areas, New Functionality Materials-Design, Preparation and Control, the Ministry of Education, Science, and Culture of Japan.

\section{REFERENCES}

1. F. P. McCandless, Ind. Eng. Chem. Process. Des. Develop., 11, 470 (1972).

2. K. Haraya, K. Obata, T. Hakuta, and H. Yoshitome,
Membrane, 11, 48 (1986).

3. R. T. Chern, W. J. Koros, B. Yui, H. B. Hopfenberg, and V. T. Stannett, J. Polym. Sci., Polym. Phys. Ed., 22, 1061 (1984).

4. T. Nakagawa, K. Takita, and A. Higuchi, Polym. Prepr. Jpn., 37, 3178 (1988).

5. K. Tanaka, H. Kita, K. Okamoto, A. Nakamura, and Y. Kusuki, Polym. Prepr. Jpn., 37, 3523 (1988).

6. M. I. Bessonov, M. M. Koton, V. V. Kudryavtsev, and L. A. Laius, "Polyimides," Plenum, New York, N. Y., 1987.

7. H. Hachisuka, H. Kito, Y. Tsujita, A. Takizawa, and T. Kinoshita, J. Appl. Polym. Sci., 35, 1333 (1988).

8. H. Hachisuka, Y. Tsujita, A. Takizawa, and T. Kinoshita, Polymer, 29, 2050 (1988).

9. H. Hachisuka, Y. Tsujita, A. Takizawa, and T. Kinoshita, J. Polym. Sci., Polym. Phys. Ed., submitted.

10. A. S. Michaels, W. R. Vieth, and J. A. Barrie, J. Appl. Phys., 34, 1 (1963).

11. A. S. Michaels, W. R. Vieth, and J. A. Barrie, J. Appl. Phys., 34, 13 (1963).

12. D. R. Paul and W. J. Koros, J. Polym. Sci., Polym. Phys. Ed., 14, 675 (1976).

13. W. J. Koros, D. R. Paul, and A. A. Rocha, J. Polym. Sci., Polym. Phys. Ed., 14, 687 (1976).

14. W. J. Koros, C. J. Patton, R. M. Felder, and S. J. Finder, J. Polym. Sci., Polym. Phys. Ed., 18, 1485 (1980).

15. R. W. Snyder and C. W. Sheen, Appl. Spectrosc., 42, 296 (1988).

16. A. G. Wonders and D. R. Paul, J. Membrane Sci., 5, 63 (1979).

17. W. J. Koros and D. R. Paul, Polym. Eng. Sci., 20, 14 (1980).

18. P. Masi, D. R. Paul, and J. W. Barlow, J. Polym. Sci., Polym. Phys. Ed., 20, 15 (1982).

19. H. Hachisuka, T. Sato, Y. Tsujita, A. Takizawa, and T. Kinoshita, Polym. J., 21, 417 (1989).

20. T. Nakagawa, K. Takita, A. Miyasato, and K. Goto, Polym. Prepr. Jpn., 35, 1163 (1986). 